Шилова О.Е.

\title{
Роль ЮНЕСКО в охране нематериального культурного наследия
}

\begin{abstract}
Аннотация: В статье рассматривается роль, которую играет «Конвенция ЮНЕСКО об охране нематериального культурного наследия» в охране нематериального культурного наследия. Рассматривается содержание Конвенции и институциональная структура органов, созданных данным актом. Исследуются примеры реализации конкретных проектов по охране нематериальных культурных ценностей. Автор делает вывод, что Конвенция сыграла первостепенную роль в защите нематериальных культурных ценностей. По его мнению это отразилось в создании списка всемирного наследия нематериальных культурных ценностей, который вызвал интерес населения различных государств и популяризировал нематериальные культурные ценности. Автор также отмечает, что именно Конвенциия создала институциональную основу охраны нематериальных культурных ценностей в лице таких органов как Межправительственный комитет по охране нематериального культурного наследия и Фонд нематериального культурного наследия, что, по его словам, позволило конкретно определить на международном уровне ответственных за охрану нематериальных культурных иенностей органов. Автор также утверждает, что именно создание Фонда нематериального культурного наследия - финансирующего совместно с государствами-членами проекты, программы и другие инициативы, направленные на охрану нематериальных культурных цеенностей - стало залогом конкретной и эффективной реализации деятельности по охране таких культурных ценностей.
\end{abstract}

Review: The article is devoted to the role of the UNESCO Convention for the Safeguarding of the Intangible Cultural Heritage in the sphere of intangible cultural heritage safeguarding. The author of the article analyzes the content of the Convention and established institutional structure. The author also studies the examples of the implementation of particular projects on intangible cultural values safeguarding. The author concludes that the Convention had played the primary role in protecting intangible cultural values. According to the author, this can be proved by the fact that one of the results of the Convention was the creation of the list of intangible cultural values. The list attracted attention of different states and popularized intangible cultural values. The author also notes that the Convention created the institutional grounds for the safeguarding of intangible cultural values and established such authorities as the Intergovernmental Committee for the Safeguarding of the Intangible Cultural Heritage and the Intangible Cultural Heritage Fund. Based on the author of the article, that allowed to assign responsible authorities at the international level. The author also states that the establishment of the Intangible Cultural Heritage Fund financed collectively by the states participating in the project as well as creation of the programs and other initiatives aimed at preservation of intangible cultural values were the guarantee of an efficient execution of activities on preservation of cultural values.

Ключевъе слова: Международное право, ЮНЕСКО, Конвенция, культурное наследие, нематериальные культурные ценности, наследие, охрана, защита, Фонд НКН, список НКЦ.

Keywords: International law, UNESCO, Convention, cultural heritage, intangible cultural values, heritage, safeguarding, protection, Intangible Cultural Heritage Fund, List of Intangible Cultural Heritage, National Cultural Center.

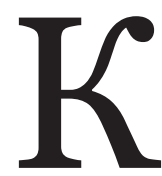

онвенция ЮНЕСКО об охране нематериального культурного наследия (далее: Конвенция) принятая государствами-членами этой организации еще 11 октября 2003 г. и вступившая в силу после ее ратификации отдельными государствами-членами в 2006 г. ознаменовала новый этап в международно-правовой защите нематериальных культурных ценностей. Действительно, данный акт стал первым в своем роде международно-правовым актом в сфере защиты нематериальных культурных ценностей.

Неудивительно что данный акт был принят и разработан именно сегодня, так как стремительное углубление глобализационных процессов на рубеже XX - XXI веков стало основным фактором появления данной Конвенции как и ряда других актов ЮНЕСКО, направленных на защиту культурных ценностей (см. например Конвенция ЮНЕСКО от 2005 г. 
«Об охране и поощрении разнообразия форм культурного самовыражения»). Цель принятия и разработки таких актов заключается в противодействии отрицательному воздействию феномена глобализации в сфере культуры посредством защиты культурных ценностей от отрицательного воздействия на них массовой глобализированной и гармонизированной культуры. Иначе говоря, основные акты ЮНЕСКО в данной сфере направлены именно на противодействие негативным последствиям вызванным либерализацией глобального товарооборота между странами, который привел к гармонизации культуры, стиранию культурных особенностей и различий между государствами и народами. Как следствие, данные международно-правовые акты направлены на преодоление полного вымирания местной (национальной) культуры.

Стоит отметить, что прецеденты международно-правового регулирования данных вопросов редки и отличались своей незначительностью и неэффективностью в плане защиты нематериальных культурных ценностей. По большей части речь шла о документах рекомендательного характера, не имеющих юридической силы и посему не способных оказать существенного влияния на защиту культурных ценностей. Большинство документов ЮНЕСКО по данному вопросу доселе ограничивалось либо сугубо исследовательской направленностью ${ }^{1}$, либо просто декларативным характером²

Конвенция впитала в себя опыт предыдущих документов разработанных ЮНЕСКО 3 . В первую очередь она впитала в себя принципы Всеобщей декларации ЮНЕСКО о культурном разнообразии от 2 ноября 2001 г., а также более старого акта, также разработанного ЮНЕСКО - Конвенции об охране всемирного культурного и природного наследия от 16 ноября 1972 г.

Более того, если ограничиться сугубо вопросами охраны нематериальных культурных

\footnotetext{
${ }^{1}$ Cм. например K. Stenou, L'Unesco et la géstion de la diversité culturelle : bilan et stratégie, 1946-2004, Etude réalisée par la Division des politiques culturelles et du dialogue interculturel de l'Unesco, Paris, 2004, 25 P.

${ }^{2}$ Так, например, в рамках ООН была разработана и принята Всеобщая декларация ЮНЕСКО о культурном разнообразии от 2 ноября 2001 г.

${ }^{3}$ См. подробнее например Костин А.C. Костина А.B. Сохранение нематериального культурного наследия народов РФ как приоритет культурной политики РФ в XXI веке//Культурная политика. 2008. - № 3. С. 5971.
}

ценностей, а не культурных ценностей вообще, то придется согласиться, что рассматриваемая здесь Конвенция стала беспрецедентным международно-правовым документом. Действительно, все инициативы ЮНЕСКО в данной сфере до принятия данной конвенции ограничивались лишь двумя проектами: «Живое человеческое достояние» (“Trésors humains vivants"4), которое был создан еще 1993 г. и направлен на создание списка живых культурных ценностей, а также Прокламацией ЮНЕСКО «Шедевры устного и нематериального наследия человечества» 5 . Так, на основе последнего документа ЮНЕСКО в 2001 г. был принят документ ${ }^{6}$, провозглашающий список конкретных нематериальных культурных ценностей среди которых мы обнаружим: лингвистические и артистические культурные ценности.

Таким образом, если охрана культурных ценностей в целом уже получила довольно обширное международно-правовое признание, то в более узкой сфере охраны нематериальных культурных ценностей на международном уровне до недавнего времени было сделано немного. Рассматриваемая здесь Конвенция стала первым в таком смысле универсальным актом, а все предпринятые до этого меры и акты ограничивались на международном уровне лишь региональными инструментами защиты нематериальных культурных ценностей

Стоит обратить внимание на необходимость создания такого, отдельного документа, регулирующего исключительно вопросы охраны именно нематериальных культурных ценностей. Действительно, в отличие от материальных культурных ценностей, охрана которых может быть произведена посредством например реставрации или реституции, нематериальные ценности по природе своей исчезнув не могут быть восстановленными ввиду своего нематериального характера. Это создает особые сложности с нематериальным культурным наследием бедных с экономической точки зрения государств Африки и Латинской Америки, которые - в отличии от государств западной Европы и Северной

\footnotetext{
${ }_{4}^{4}$ DOC. $142 \mathrm{EX} / 18$

${ }^{5}$ www.unesco.ru/media/docs/2010/Shedevry.pdf

${ }^{6}$ DOC 155 EX/15 Annex IV

7 Так, например в рамках Совета Европы и Европейского Союза были разработаны такие акты, направленные на охрану нематериальных культурных ценностей, как: Рамочная конвенция Совета Европы о защите национальных меньшинств от 1 февраля 1995 г. а также Европейская хартия региональных языков или языков меньшинств от 5 ноября 1992 г.
} 
Америки - не могут выделить достаточных средств на запись, оцифровку, а также другие способы «материализации» музыкальных произведений, обрядов обычаев и других нематериальных культурных ценностей, а также на создание медиатек с целью обеспечения их сохранности и доступа к ним населения.

Стоит отметить, что немаловажной заслугой рассматриваемой здесь Конвенции стало само определение того, что представляют собой нематериальные культурные ценности. Подход ЮНЕСКО к данному определению 8 неоднозначен, так как в Конвенции оно осуществляется как посредством собственно определения, так и посредством перечисления конкретных примеров нематериальных ценностей. Понятие нематериальных ценностей, закрепленное Конвенцией, является довольно широким так как включает даже такие аспекты жизнедеятельности человека как знания и навыки, празднества, ритуалы, обряды и обычаи и даже язык. Также интересен и тот факт, что выгодоприобретателями нематериального культурного наследия, то есть лицами которые могут выступать в качестве субъекта права на охрану нематериальных культурных ценностей не только народы и сообщества которые в принципе являются первыми выгодоприобретателями данного права - но также и отдельные индивиды (ст. 2).

Обязательства по принятию мер по охране нематериального культурного наследия, накладываются, как и в рамках любого другого международно-правового акта, на подписавших его государств. Конвенция однозначно определяет тот набор мер посредством которых данные обязательства могут быть исполнены государствами-участниками: идентификацией, документированием, исследованием, сохранением, защитой, популяризацией, повышением роли нематериальных культурных ценностей, а также их передачей, главным образом с помощью формального и неформального образования (ст. 3). Как мы уже отметили нематериальные культурные ценности обладают характерной особенностью - нематериальностью, которая делает их более уязвимыми, чем материальные культурные ценности. Именно поэтому среди основных мер, которые обязаны принимать государства, мы обнаруживаем такую меру как документация нематериальных культурных ценностей, которая может получить свое воплощение в соз-

\footnotetext{
${ }^{8}$ См. подробнее UNESCO, What is intangible cultural heritage?. UNESCO. 2008.
}

дании медиатек с видео и аудио материалами 9 . Остальные меры направлены не столько на, собственно, сохранение нематериальных культурных ценностей сколько на стимулирование их развития, в частности посредством популяризации и образования (ст. 14).

В качестве мер по охране нематериального культурного наследия Конвенция выделяет: составление государствами-членами списков нематериального культурного наследия, имеющегося на их территории (ст. 12); определения или создания органов по охране нематериального культурного наследия; содействия научным, техническим и искусствоведческим исследованиям, обеспечение доступа к нематериальному культурному наследию; создания учреждений, занимающихся документацией по нематериальному культурному наследию, и облегчение доступа к ним (ст. 13).

Стоит обратить внимание и на установление Конвенцией такой обязанности государствчленов как обеспечение участия широких слоев гражданского общества, сообществ, групп и, в соответствующих случаях, отдельных лиц, которые занимаются созданием, сохранением и передачей такого наследия, в процессах управления таким наследием (ст. 15). Такое участие неправительственных организаций и других представителей гражданского общества отвечает современным тенденциям децентрализации государственного и межгосударственного управления, в том числе и в сфере политики защиты культурных ценностей ${ }^{10}$.

В тексте Конвенции можно также обнаружить и такой, характерный для современных интегрированных международных отношений институт как совместное сотрудничество государств с целью охраны объектов нематериального культурного наследия (ст. 19). Стоит отметить, что данный вид сотрудничества был разработан ЮНЕСКО еще в 70-х гг. прошлого века, когда впервые международное сотрудничество в целью охраны объектов культурного наследия было предусмотрено Конвенцией ЮНЕСКО об охране всемирного культурного и природного наследия от 16 ноября 1972 г. Как пишут наши коллеги, такое сотрудничество заключающееся в технической, финансовой и

${ }_{9}^{9}$ Cм. подробнее по данному вопросу, например: Ch. Beat Graber, M. Burri Nenova, Intellectual Property and Traditional Cultural Expressions in a Digital Environment, Edward Elgar Publishing, 2008.

${ }^{10}$ См. по данному вопросу, например: F. Starr, Corporate Responsibility for Cultural Heritage: Conservation, Sustainable Development, and Corporate Reputation, Routledge, 2013. 
научной помощи и сотрудничестве - является тем более необходимым, что защита культурных ценностей довольно часто носит транснациональный характер, так как сообщества и национальные меньшинства, на защиту культурных ценностей которых направлен данный акт, нередко расположены на территориях различных государств ${ }^{11}$.

Основная масса работы по организации такого сотрудничества ложиться на плечи Межправительственного комитета по охране нематериального культурного наследия, созданного в рамках Конвенции. Так как в соответствии с Конвенцией основная нагрузка в работе по охране нематериального культурного наследия должна ложиться на плечи самих государств (ст. 24), то деятельность Комитета по большей части ограничивается предоставлением финансовой помощи государствам с целью реализации на месте мер по охране объектов культурного наследия их собственными силами.

Конкретно, предоставление международной помощи по охране нематериальных культурных ценностей осуществляется Комитетом, либо по заявкам государств-участников Конвенции (ст. 23), либо посредством участия в реализации проектов разработанных на уровне самой организации (ЮНЕСКО). В том что касается первого вида помощи - то есть помощи реализуемой Комитетом по заявкам государств - то она осуществляется посредством реализации проектов и программ, одобренных самим Комитетом. Рассмотрение заявки государства-члена на оказание помощи дает место последующим консультациям между членами Комитета и представителями государства-члена, в случае одобрения такого проекта или программы между Комитетом и соответствующим государством заключается договор о предоставлении помощи и реализации конкретных действий по охране нематериальных культурных ценностей. Финансовые средства, предназначенные для реализации таких проектов и программ, предоставляются Комитетом за счет «Фонда нематериального культурного наследия» ((далее: Фонд) см. подробнее ниже), а также финансового участия самих государств. Реже, они реализуются за счет средств бюджета самой организации (ЮНЕСКО), но во всех случаях международная организация пытается при-

\footnotetext{
${ }^{11}$ См. подробнее например E. Clement, Le concept de responsabilité collective de la communauté internationale pour la protection des bien culturels dans les conventions et recommandations de l'UNESCO, Revue belge de droit international, 1993, pp. 534-551
}

влечь к финансовой контрибуции и самих, заинтересованных государств.

Стоит отметить, что предоставление международной помощи Комитетом является наиболее значимой деятельностью ЮНЕСКО в сфере охраны нематериальных культурных ценностей. Можно, без преувеличения утверждать, что реализация проектов и программ при финансовой и технической поддержки Комитета является единственным наиболее эффективным средством международно-правовой охраны нематериальных культурных ценностей. Действительно, за менее, чем десятилетний срок деятельности ЮНЕСКО по реализации международной помощи в сфере охраны нематериальных культурных ценностей было инициировано более сотни проектов, программ и планов по реализации конкретных действий по охране таких культурных ценностей в различных странах мира. Среди них: план действий по охране баульских (бангладешский фольклор) песен (Action Plan for the Safeguarding of Baul Songs); программа по охране чопских музыкальных оркестров в республике Мозамбик (Safeguarding the Chopi Timbila tradition in Mozambique); программа возрождения традиционного изготовления одежды из коры дерева в Уганде (Revitalization of bark cloth making in Uganda) и т.п. Более того, предоставление Комитетом международной помощи осуществляется по двум направлениям: собственно, охраны нематериальных культурных ценностей (указанные проекты), которая является основным направлением деятельности Комитета, а также защиты нематериального культурного наследия, нуждающегося в срочной охране ${ }^{12}$.

Создание списка всемирного нематериального культурного наследия также стало важным вкладом Конвенции в сфере охраны объектов нематериального культурного наследия. Гл. IV текста конвенции обязывает соответствующие органы Конвенции (Комитет) создать два списка: список нематериального культурного наследия (ст. 16) и список нематериального культурного наследия, нуждающегося в срочной охране (ст. 17). Данные списки обладают как, сугубо, охранительной функцией, что мы можем обнаружить в

\footnotetext{
${ }^{12}$ Одной из программ Комитета по предоставлению международной помощи с целью защиты объектов нематериального культурного наследия, нуждающихся в срочной охране стал «Инвентарь нематериального культурного наследия в Республике Мали, нуждающегося в срочной охране» (Inventory of intangible cultural heritage in Mali with a view to its urgent safeguarding)
} 
случае со списком объектов нуждающихся в срочной охране, так и ознакомительной, или популяризирующей функцией, что мы можем обнаружить в случае с общим списком нематериального культурного наследия. Данные списки - в отличие от ставшего уже популярным списка всемирного наследия ЮНЕСКО - не направлены на внесение в них объектов имеющих исключительное значение для человечества, а направлены на придание значения нематериальным культурным ценностям посредством ознакомления с ними общественности, что предполагает внесения в такие списки даже тех культурных ценностей, которые имеют значение лишь для ограниченного круга лиц ${ }^{13}$. Такой подход составителей текста конвенции к нематериальным культурным ценностям вполне понятен, так чаще всего речь идет о несовершенных (примитивных) формах искусства, ремесленничества, обрядов и других форм культурного наследия, относимых чаще всего к фольклору, чем к «высоким» формам искусства. Они в принципе имеют меньшее значение в глазах современного глобализированного потребителя культурного продукта, касаются по большей части национальных меньшинств, а не граждан какого-либо государства в целом и посему имеют меньшее значение ${ }^{14}$. Как следствие, в списке определенном Комитетом конвенции мы можем обнаружить такие культурные ценности как: древнегрузинский способ виноделия; саманский танец; соколиную охоту; традиционные карабахские игры на лошадях; китайский театр теней; французскую кухню и т.п. Согласимся, не все из указанных видов культурного выражения имеют одинаковое значение и вряд ли отдельные из них можно охарактеризовать (наподобие того как это делается Конвенцией об охране всемирного культурного и природного наследия) как исключительные или имеющие всемирное

\footnotetext{
${ }^{13}$ На такую более чем скромную (в сравнении со списком объектов всемирного культурного наследия) роль списков нематериального культурного наследия не раз обращалось внимание в науке. См. напримep C. Forest. International Law and the Protection of Cultural Heritage Routledge, 2012. См. также Белугина Г.А. Актуализация нематериального культурного наследия в музейно-выставочной и туристско-рекреационной деятельности. Дисс. канд. Культ. Ярославль. 2012.

14 T.M. Schmitt, The UNESCO Concept of Safeguarding Intqngible Cultural Heritage: its Background and Marakeshi Roots. International Journal of Heritage Studies. 2008.
}

значение культурные ценности. В тоже время, как мы уже отметили, при создании данного списка преследовались совершенно другие цели: в первую очередь, он выполняет ознакомительную функцию.

Стоит отметить, что одним из наиболее значимых нововведений рассматриваемой здесь Конвенции стало создание международных институциональных основ защиты объектов нематериального культурного наследия. А именно: создание «Фонда нематериального культурного наследия» (гл.VI) и создание органов самой конвенции (гл. II). Именно создание таких институциональных основ международной охраны объектов нематериального культурного наследия стало залогом повышения качества и эффективности защиты данных объектов, так как впервые на международном уровне были определены органы ответственные за сохранность нематериальных культурных ценностей.

Фонд нематериального культурного наследия (далее: Фонд) является целевым фондом, средства которого направляются на проекты и программы по защите нематериальных объектов культурного наследия (см. подробнее выше). Распределение средств Фонда по проектам осуществляется по инициативе Комитета, тогда как источники пополнения средств Фонда многочисленны ${ }^{15}$. В первую очередь они состоят их обязательных взносов государствчленов, которые составляют 1 процент от общих взносов государств в бюджет ЮНЕСКО, а также средств самой организации ЮНЕСКО (ст. 25). Помимо таких взносов, которые являются обязательными для государств-членов, существуют также и добровольные пожертвования государств, которые могут быть как целевыми так и нецелевыми. Так, например, добровольными нецелевыми контрибуторами бюджета Фонда на сегодняшний день являются: Болгария, Китай, Венгрия, Индонезия, Әстония и др. Другие государства - также на добровольной основе - предоставляют средства в бюджет Фонда на целевые проекты и программы: Монако, Норвегия, Нидерланды, Испания, Турция, Япония и др.

Другой институциональной структурой, которая имеет немаловажное значение для охраны нематериального культурного наследия на международном уровне (в рамках

15 По вопросам пополнения финансовых средств фонда см. например: L. Lixinski, Intangible Cultural Heritage in International Law, Oxford University Press, 2013 . 
ЮНЕСКО) является Межправительственный комитет по охране нематериального культурного наследия (ст. 5). Стоит отметить, что Конвенция, как и подобает большинству универсальных международно-правовых инструментов создала и другие органы в рамках Конвенции, но тем не менее, основная роль в сфере охраны объектов нематериального культурного наследия играет именно указный Комитет. Это подтверждается самим текстом Конвенции, в которой глава, касающаяся органов Конвенции (гл. 2), посвящает лишь по одной статье Генеральной ассамблее государств-участников Конвенции, а также Секретариату ЮНЕСКО, тогда как остальные статьи данной главы посвящены исключительно работе Комитета.

В отличие от репрезентативного органа Конвенции (Генеральная ассамблея), где по идее международного права должны быть представлены все страны участники Конвенции, Комитет представляется скорее как рабочий орган Конвенции. Сегодня он состоит их 24 представителей государств-членов, равномерно представляющих все регионы (континенты) мира. Тем не менее, деятельность Комитета не ограничивается участием представителей государств-членов. К своей работе он привлекает и внешних субъектов сферы культуры, что еще раз подтверждает современный характер Конвенции, так как в соответствии с данным актом к работе Комитета могут привлекаться, в частности, неправительственные организации, обладающие признанной компетенцией в области нематериального культурного наследия.

Будучи подотчетным Генеральной ассамблее Конвенции органом, основной функцией Комитета является: подготовка и представление на утверждение Генеральной ассамблеи оперативного руководства по выполнению Конвенции; рассмотрение докладов государств-участников и их резюмирование для Генеральной ассамблеи и т.п. (ст. 7). В тоже время, де-факто именно Комитет выполняет основные функции в сфере деятельности по охране нематериальных культурных ценно- стей на международном уровне, вменённых государствами-членами организации (ЮНЕСКО). Основной среди них конечно же является «содействие достижению целей Конвенции, поощрение и обеспечение мониторинга ее выполнения", а также “подготовка рекомендаций о мерах по охране нематериального культурного наследия" (ст. 7 а) и в)). В тоже время Комитету вменены в обязанность и такие не маловажные функции как: подготовка и представление на утверждение Генеральной ассамблеи проекта плана использования средств Фонда нематериального культурного наследия и изыскание путей увеличения его ресурсов; а также рассмотрение заявок, представляемых государствами-участниками, и принятие решений в соответствии с разработанными Комитетом объективными критериями, касающимися: включения в списки и отбора предложений, на включение в списки всемирного нематериального культурного наследия предоставления международной помощи.

Итак, Конвенция ЮНЕСКО об охране нематериального культурного наследия играет первостепенную роль в охране нематериального культурного наследия. Во-первых, это отразилось в создании списка всемирного наследия нематериальных культурных ценностей, что вызвало интерес населения различных государств и популяризировало объекты нематериального культурного наследия. Во-вторых, Конвенция создала институциональную основу охраны нематериальных культурных ценностей в лице таких органов как Межправительственный комитет по охране нематериального культурного наследия и Фонд нематериального культурного наследия, что позволило конкретно определить ответственных за охрану нематериальных культурных ценностей органов. Наконец, создание Фонда нематериального культурного наследия, финансирующего совместно с государствами-членами проекты, программы и другие инициативы, направленные на охрану нематериальных культурных ценностей, стало залогом конкретной и эффективной реализации деятельности по охране таких культурных ценностей.

\section{Библиография:}

1. Белугина Г.А. Актуализация нематериального культурного наследия в музейно-выставочной и туристскорекреационной деятельности. Дисс. канд. культ. Ярославль. 2012.

2. Костин А.С. Костина А.В. Сохранение нематериального культурного наследия народов РФ как приоритет культурной политики РФ в XXI веке//Культурная политика. 2008. - № 3. С. 59-71. 
3. Ch. Beat Graber, M. Burri Nenova, Intellectual Property and Traditional Cultural Expressions in a Digital Environment, Edward Elgar Publishing, 2008.

4. E. Clement, Le concept de responsabilité collective de la communauté internationale pour la protection des bien culturels dans les conventions et recommandations de l'UNESCO, Revue belge de droit international, 1993, pp. 534-551

5. C. Forest. International Law and the Protection of Cultural Heritage Routledge, 2012.

6. L. Lixinski, Intangible Cultural Heritage in International Law, Oxford University Press, 2013.

7. T.M. Schmitt, The UNESCO Concept of Safeguarding Intqngible Cultural Heritage: its Background and Marakeshi Roots. International Journal of Heritage Studies. 2008.

8. F. Starr, Corporate Responsibility for Cultural Heritage: Conservation, Sustainable Development, and Corporate Reputation, Routledge, 2013.

9. K. Stenou, L'Unesco et la géstion de la diversité culturelle : bilan et stratégie, 1946-2004, Etude réalisée par la Division des politiques culturelles et du dialogue interculturel de l'Unesco, Paris, 2004, 25 P.

10. UNESCO, What is intangible cultural heritage ?. UNESCO. 2008.

\section{References (transliterated):}

1. Belugina G.A. Aktualizatsiya nematerial'nogo kul'turnogo naslediya $v$ muzeino-vystavochnoi $\mathrm{i}$ turistskorekreatsionnoi deyatel'nosti. Diss. kand. kul't. Yaroslavl'. 2012.

2. Kostin A.S. Kostina A.V. Sokhranenie nematerial'nogo kul'turnogo naslediya narodov RF kak prioritet kul'turnoi politiki RF v XXI veke//Kul'turnaya politika. 2008. - № 3. S. 59-71.

3. Ch. Beat Graber, M. Burri Nenova, Intellectual Property and Traditional Cultural Expressions in a Digital Environment, Edward Elgar Publishing, 2008.

4. E. Clement, Le concept de responsabilité collective de la communauté internationale pour la protection des bien culturels dans les conventions et recommandations de l'UNESCO, Revue belge de droit international, 1993, pp. $534-551$

5. C. Forest. International Law and the Protection of Cultural Heritage Routledge, 2012.

6. L. Lixinski, Intangible Cultural Heritage in International Law, Oxford University Press, 2013.

7. T.M. Schmitt, The UNESCO Concept of Safeguarding Intqngible Cultural Heritage: its Background and Marakeshi Roots. International Journal of Heritage Studies. 2008.

8. F. Starr, Corporate Responsibility for Cultural Heritage: Conservation, Sustainable Development, and Corporate Reputation, Routledge, 2013.

9. K. Stenou, L'Unesco et la géstion de la diversité culturelle : bilan et stratégie, 1946-2004, Etude réalisée par la Division des politiques culturelles et du dialogue interculturel de l'Unesco, Paris, 2004, 25 P.

10. UNESCO, What is intangible cultural heritage?. UNESCO. 2008. 